\title{
Identidades "Raciais" e Identidades Nacionais: as Representações do Corpo Negro na Construção do "Estilo Brasileiro de Jogar Futebol
}

\author{
Bruno Otávio de Lacerda Abrahão* \\ Próspero Brum Paoli* \\ Antonio Jorge Soares ${ }^{* * *}$
}

\begin{abstract}
Resumo: os autores analisaram as representações socialmente construídas sobre a "raça negra" e a sua contribuição para a elaboração identitária do "estilo brasileiro de jogar futebol". Investigaram a literatura antropológica do tema e realizaram entrevistas semiestruturadas com os treinadores das categorias de base e profissional, questionando-os se reconheciam diferenças nas formas de jogar no Brasil, em função das diferentes regiões. As respostas atualizam a tradição do "estilo à brasileira" - o futebol-arte polarizando-o futebol-força. As justificativas sobre a estética do estilo brasileiro se valeram da ideologia da mestiçagem e da participação dos negros nesse processo.
\end{abstract}

Palavras-chave: futebol. Identidade brasileira. Representações raciais.

\section{INTRODUÇÃo}

As nações compartilham características que são pensadas como peculiares de seu povo. A construção dessas representações hegemônicas ${ }^{1}$ se vale das lutas por territórios simbólicos elaborados pela seleção de certos traços de distinção em relação ao "outro".

Dentre o processo da construção simbólica do "nacional", um deles é orientado pelas análises das virtudes esportivas baseadas nos "estilos de jogar futebol" (ARCHETTI, 2003). Nessa direção,

\footnotetext{
"Centro Universitário Metodista Izabela Hendrix. Belo Horizonte, MG. Brasil. E-mail: bolabra@gmail.com

**Universidade Federal de Viçosa, Viçosa, MG. E-mail: prosperopaoli@bol.com.br *****Universidade Federal do Rio de Janeiro, RJ, Brasil. E-mail: ajsoares@globo.com

${ }^{1}$ Quando uma representação prevalece nas práticas sociais compartilhadas por membros de um grupo estruturado - uma nação, por exemplo - elas se tornam hegemônicas. Ver Arruda (1998).
} 
os "estilos nacionais de jogar futebol" seriam explicados, em parte, pela perspectiva dos debates identitários que tomam o futebol como metonímia da nação. Tomando a perspectiva de DaMatta (1982), na medida em que está inserido na sociedade brasileira, o futebol dramatiza os significados dessa cultura. Sendo assim, o "estilo à brasileira" se origina de elaborações, quase imediatas, da identidade do "ser brasileiro":

os desempenhos de seleções nacionais deveriam expressar igualmente as autopercepções que cada um confere para si, traduzidas na personalidade, fisionomia ou "jeito" de cada povo, evidenciados na garra argentina ou uruguaia ou na malícia brasileira, por exemplo (TOLEDO, 2002, p. 68).

A discussão sobre o "estilo brasileiro de jogar futebol" éinspirada a partir das idiossincrasias sobre a constituição étnica conceitualizada como diferencial no caráter e na maneira de ser do "povo brasileiro". Através das figuras dos especialistas ${ }^{2}$ de futebol (TOLEDO, 2002), as nações desenvolveram diferentes percepções dos seus estilos de jogar futebol que são explicados, em parte, pelas ideologias, identidades e formação histórica de cada povo. Nesse sentido, o futebol oferece um espaço privilegiado para pensar os mecanismos e processos da construção da identidade brasileira.

Dessa forma, o objetivo deste artigo é analisar as representações socialmente construídas sobre a "raça negra"3 e a sua contribuição para a elaboração identitária do "estilo brasileiro de jogar futebol". ${ }^{4}$

\footnotetext{
${ }^{2}$ Toledo cita como sendo esses "especialistas" os torcedores, os dirigentes, os jogadores, os treinadores e os cronistas esportivos.

${ }^{3}$ As categorias de classificação racial utilizadas pelo IBGE são brancos, pretos e pardos, enquanto o movimento negro brasileiro utiliza apenas os termos "negro" e "branco" para se referir ao sistema de classificação que tem sido utilizado pela mídia e pelos artigos acadêmicos (TELLES, 2003). Desse modo, utilizaremos o termo "raça negra" quando estivermos nos referindo à análise de uma categoria abrangente e identitária de análise e os termos "pretos", "pardo" ou "branco" quando estivermos fazendo uma análise descritiva.

${ }^{4}$ Nossa intenção é gerar debate entre acadêmicos uma vez que as técnicas de jogo, os estilos e a apreciação estética têm sido notavelmente ausentes de trabalhos eruditos, segundo Giulianotti (2002).
} 


\section{Metodologia}

Identidades, representações e memória encontram-se interrelacionadas. Memória e história são presentes na produção de fontes orais por meio dos quais as identidades de sujeitos históricos são reconhecidas e analisadas como integrantes da tessitura constitutiva da historia. Com efeito, a memória, além de outros processos culturais, é também uma das fontes para expressão das identidades raciais. As lembranças são disseminadas através das gerações que, por sua vez, influenciam ou determinam as representações hodiernas (DELGADO, 2006).

o ato de relembrar insere-se entre as possibilidades múltiplas de registros do passado, elaboração das representações e afirmação de identidades construídas na dinâmica da história. Portanto, a memória passa a se constituir como fundamento de processos identitários, referindo-se a culturas, comportamentos e hábitos coletivos. Dessa forma, história e memórias, enredadas na trama da reconstituição temporal e espacial, contribuem para a consolidação da consciência de pertencimento ou de não-pertencimento dos sujeitos históricos a organizações, grupos, instituições, etnias, países (DELGADO, 2006, p.46)

Para tanto, investigamos a literatura antropológica sobre o tema e, tomando a perspectiva de que os registros orais são suportes de memória coletiva (DELGADO, 2006), realizamos, no segundo semestre de 2005, entrevistas semiestruturadas com os treinadores das categorias de base $\mathrm{e}^{5}$ e com o treinador da equipe principal do Cruzeiro Esporte Clube, de Belo Horizonte/MG. A pergunta que conduziu a entrevista foi: "Você observa diferença na forma de jogar entre os atletas das diferentes regiões do Brasil? Quais são?".

De acordo com Damo (2002) as conquistas do Grêmio Football Porto Alegrense desencadeou um mal estar no cenário nacional em relação ao "estilo brasileiro de jogar futebol". A eficácia de um

${ }^{5} \mathrm{~A}$ saber: mirim, pré-infantil, infantil, juvenil e júnior.

Movimento, Porto Alegre, v. 17, n. 02, p. 195-210, abr/jun de 2011. 
estilo de jogo - o "futebol-força"- traduzido nas conquistas do clube na década de 90 fazia que aquele estilo fosse interpretado como diferente e até mesmo oposto ao brasileiro, identificado como o "futebol-arte". O dilema reside no fato de que sendo o Grêmio um clube gaúcho era, portanto, brasileiro, mas paradoxalmente o jogo praticado por esse clube afrontava uma concepção de futebol que é, em si mesmo, sinônimo da brasilidade. A tensão entre o sul e o Brasil faz parte da construção identitária do "ser brasileiro" (OLIVEN, 2006).

A categoria "futebol-força" não é reconhecida somente pelo estilo de jogo praticado pelo Grêmio, mas também por outros clubes da região sul do Brasil. Com efeito, teríamos, no plano das representações construídas sobre os diferentes estilos de futebol praticados no Brasil, o "futebol-arte" e o "futebol-força" sendo um a antítese do outro. Enquanto o último se caracterizaria por um estilo de jogar pelos clubes da região sul do Brasil, sobretudo no Rio Grande do Sul, o primeiro seria praticado nas demais regiões do Brasil, fundamentalmente tomando o Rio de Janeiro como referência. Estas representações são internalizadas discursivamente pelos diferentes atores (jornalistas, treinadores, jogadores) que compõem o "campo profissional do futebol".

Sendo assim, nossa intenção ao questionar os treinadores sobre as diferenças no modo de jogar nas diferentes regiões do Brasil seria acionar as categorias de pertencimento a determinados componentes identitários a partir das representações que os especialistas possuem sobre os diferentes estilos de futebol que coexistem no Brasil, quais sejam: o "gaúcho" - uma metonímia do futebol-força - e o "nacional" - a quintessência do futebol-arte. Nosso objetivo foi acionar, a partir da memória dos entrevistados, as idiossincrasias sobre o "ser gaúcho" e o "ser brasileiro" a partir das lembranças desses atores sociais sobre o futebol.

O campo esportivo, entendido como um campo simbólico de manifestação de elementos da cultura, reflete e atualiza o conflito entre a "periferia" - o Rio Grande do Sul, na qualidade de Estado fronteiriço - e o "centro" do País, nomeadamente Rio de Janeiro e 
São Paulo. Os atributos que distinguiriam uma categoria da outra, aplicados ao campo de futebol, são traduzidos em termos de "estilos" que refletiriam o ethos de cada uma das categorias (GASTALDO; LEISTNER, 2003; OLIVEN, 2006).

Para Damo (2002), o estilo do futebol gaúcho resulta da apropriação, por parte de torcedores, dirigentes, treinadores, jogadores ou cronistas esportivos, de um discurso de culto às tradições regionais. Estes discursos localizam o Rio Grande do Sul numa posição diferenciada em relação ao "centro" do Brasil: "através do enfrentamento e, portanto, da disjunção, o futebol permite uma comparação entre o 'nós', os gaúchos, e os 'outros', sejam eles 'cariocas', paulistas ou brasileiros em geral" (DAMO, 2002, p. 135).

Analisando os mecanismos sociais da construção da "identidade gaúcha", Oliven (2006) observou que esse modelo se sustenta na crença de um passado que teria existido na região pastoril da campanha no sudoeste do Rio Grande do Sul e na figura real e idealizada do gaúcho. É em torno desse eixo que giram os debates sobre a identidade gaúcha. As características especiais do Rio Grande do Sul estariam relacionadas ao modo como aquele estado foi colonizado, sua localização e sua história. Essa construção é excludente e se faz à custa da metade do território sul-riograndense e também de grande parte dos seus grupos sociais. Apesar da notável projeção econômica e política dos descendentes de colonos de origem alemã e italiana no Rio Grande do Sul, a construção da "identidade gaúcha" não as inclui, assim como também não o faz em relação ao negro e ao índio "que comparecem no nível das representações de forma extremamente pálida" (OLIVEN, 2006, p. 155).

Os dados mais atualizados a respeito da demografia da população do Rio Grande do Sul são oriundos do Programa Nacional de Amostras de Domicílios, publicado em 2006, através do qual se constata que aquele Estado é o segundo "mais claro" do Brasil, com $82,3 \%$ da população se declarando branca. Comparando os dados demográficos do Rio Grande do Sul aos dados mais atualizados sobre 
o Brasil, provenientes do Censo 2010, vê-se que o percentual dos brasileiros que se declaram "branco" é da ordem de 47,7\%. Os demais percentuais são 7,6\% de pretos, $43,1 \%$ de pardos, $0,4 \%$ de indígenas e $0,1 \%$ de amarelos ${ }^{6}$. Esses valores revelam como o povo brasileiro é altamente miscigenado enquanto o Rio Grande do Sul, ao contrário, se apresenta como um estado mais homogêneo no que diz respeito à declaração da cor auto-percebida dos seus habitantes. Como efeito, poderíamos pensar que o "ser gaúcho" se aproxima do "ser branco" e teria como seu par comparativo e contrastivo o "ser brasileiro".

As décadas de 20 e 30 foram "tempos de apropriação" do esporte inglês enquanto símbolo da identidade nacional brasileira (FRANZINI, 2003, p. 11). Foi nesse período, por exemplo, que Gilberto Freyre reinterpretou o caráter nacional de forma otimista atribuindo um sentido positivo ao debate da miscigenação no Brasil e se transformou num daqueles intelectuais responsáveis pela construção imaginária do "Brasil mestiço" (FREYRE, 1981).

A boa campanha da seleção brasileira na Copa do Mundo de 1938 fez surgir um forte discurso identitário, a partir do futebol, estabelecendo um estilo brasileiro, focado no toque de bola, nos dribles, nas jogadas criativas de seus jogadores e manteve essa fama com as gerações dos anos 60 e 70. A partir da Copa de 38, o futebol alcançara no Brasil seu reconhecimento como uma "verdadeira instituição nacional", nas palavras de Gilberto Freyre (SOARES, 2003; FRANZINI, 2003).

Respondendo ao repórter quando questionado sobre o motivo do sucesso da seleção brasileira na Copa da França de 38, Freyre disse que o sucesso da seleção brasileira teria ocorrido a partir do momento em que incorporou, no seu quadro, o afro-brasileiro ${ }^{7}$. O futebol somente passou ser um esporte nacional quando, assim como o sentimento de ser brasileiro, conseguiu reunir, em uma mesma

\footnotetext{
${ }^{6}$ www.censo2010.ibge.gov.br, acessado em 23/05/2011. Até a data de acesso o censo ainda não havia disponibilizado os dados relativos à demografia dos Estados Brasileiros. Os dados mais atualizados foram aqueles do PNAD, em 2006.

${ }^{7}$ Artigo jornalístico intitulado "Foot-Ball mulato", para o jornal "Diários Associados", em 17/06/ 1938.
} 
construção discursiva, as diferentes "raças" e etnias na cultura brasileira, a saber: os "brancos", os "negros" e, principalmente, o produto resultante dessa conciliação, "os mulatos ainda mais brasileiros". A contribuição da dança africana, que estaria entranhada racial e culturalmente na sociedade brasileira, teria sido o que criou para Freyre uma forma dançante no "seu" futebol. Assim, Freyre foi um dos que afirmou enfaticamente a singularidade do "estilo brasileiro de jogar futebol" (SOARES, 2003).

Soares (1998) observou que alguns cientistas sociais assumiam uma atitude pouco distanciada ao analisar a contribuição do futebol brasileiro para a construção da identidade nacional. Ao invés de questionarem as representações essencializadas sobre a relação "raça" e futebol, acabaram por reproduzi-las e ou reconstruí-las. De fato, a "legitimidade" do discurso científico, ao invés de discutir os mecanismos de construção da identidade nacional e "racial", contribuiria para reforçá-las e/ou propagá-las.

Damo (2002) apresenta, respectivamente, as polarizações da identidade do futebol brasileiro comparando-a em relação ao futebol europeu: artístico x competitivo; espetáculo x eficiência; dionisíaco x apolíneo; barroco x clássico; intuitivo x racional; natureza x cultura; dom $\mathrm{x}$ aprendizado; futebol-arte $\mathrm{x}$ futebol-força. Gastaldo e Leistner (2003) observaram que as críticas que o discurso jornalístico do "centro do país" endereçava ao "futebol gaúcho" se valiam da avaliação que esse estilo era desleal - ou violento - e de forte marcação forte e disciplina tática: um estilo "europeizado", a antítese do "futebolarte". O romancista Érico Veríssimo, por sua vez, publicou uma crônica indicando que o adjetivo "viril" é a característica mais exigida e apreciada pelos gaúchos ${ }^{8}$. A tradição de guerras e conflitos presentes na história do Rio Grande do Sul permeia o discurso dos habitantes daquele Estado e dramatiza a identificação do "futebolforça".

Essas idiossincrasias sobre o "povo gaúcho" se refletem nas elaborações sobre a forma como o futebol é jogado naquele Estado.

${ }^{8}$ Apresentada por Oliven (2006, p. 63 - 64).

Movimento, Porto Alegre, v. 17, n. 02, p. 195-210, abr/jun de 2011. 
Observemos como os especialistas entrevistados internalizaram as representações identitárias sobre as diversas maneiras como o futebol é praticado no Brasil.

Eu acredito que tem o fato da cultura da proximidade com a Argentina e o Uruguai que tem um futebol mais pegado e de marcação. Percebe no Sul um futebol mais de força, no Rio de Janeiro você tem um futebol mais solto. [...] Existem diferenças daquilo que uma equipe apresenta em campo (entrevistado 1).

O biótipo dos meninos dos diferentes estados do Brasil influencia na maneira dos times dessas regiões jogarem. As equipes do sul são mais fortes, mais pegada, mais choque. Na nossa região tem um jogo mais cadenciado, jogadores com outro biótipo e um jogo mais bonito. No nordeste, por exemplo, é muita correria (entrevistado 3).

O futebol gaúcho há pouco tempo atrás era muita força, muita jogada aérea, muito chutão. Em um tempo atrás eu achava isso do futebol gaúcho muita força, muito... (entrevistado 4).

O sul tem um sistema de marcação mais forte, o sudeste principalmente no Rio de Janeiro é um futebol mais solto, mais espetáculo, em São Paulo e Minas você vê uma compactação maior, um futebol de mais marcação e chegada, a região norte e nordeste com jogadores de muita velocidade, isso aí diferencia muito. Essa diferença eu atribuo ao nosso país, que é muito grande e é um país que respira futebol... Eu sempre digo que existem várias culturas, uma cultura do nordeste que é uma cultura mais liberal. No sul a cultura é mais de disciplina, mais determinação, então, é mais em cima da região mesmo. E essa cultura local influencia muito na forma de jogar (entrevistado 6).

Na medida em que identidades são representações formuladas em oposição a outras identidades, o que se busca são justamente as diferenças para servir ao contraste. Para destacar a singularidade da identidade do futebol brasileiro os especialistas espontaneamente 
se valeram da polarização entre o futebol "europeu", "do Sul" ou "gaúcho" em contraposição ao "estilo" como o futebol é praticado nas outras partes do Brasil. Essa dicotomia apareceu nas elaborações de todos os entrevistados revelando as formas internas de diferenciação do "regional". Nesse aspecto, "virilidade" é reconhecida pelo "outro" como uma categoria diferencial dos gaúchos que é traduzida num estilo de jogo pautado pela força, marcação e disciplina tática. Estas categorias revelam o olhar do "outro" sobre o diferencial daquilo que seria o "o estilo gaúcho de jogar futebol".

Questionamos, então, quais seriam as causas que configuraria as identidades de cada estilo:

No nordeste, as coisas vêm mudando, mas ainda eu acho que ainda mantém as raízes sim. A população nossa ela é bem diversificada, primeiro item é isso (entrevistado 2).

Essa característica do futebol do sul eu acho que pela cultura, pela civilização mais europeia, eu acho que é por isso. Este estilo determina a forma de jogar da região sul é pela própria imigração desse povo europeu para o sul. O estilo que dentro do Brasil se contrapõe ao estilo do sul é o futebol carioca, que é um jogo mais cadenciado, mais jogado de muita qualidade técnica (entrevistado 4)

Esse aspecto físico está relacionado a colonização, né? Você tem no sul o alemão, italiano, holandês como povos que concentraram a colonização no sul do país, você tem no nordeste o africano, o indígena, um pouco de holandês na região de Pernambuco, mas é aquele pessoal com o biótipo menos favorecido. Essa colonização implicou na forma das pessoas que nasceram naquelas regiões jogarem. $\mathrm{O}$ clima no sul é um clima mais frio aproximado com o da Europa, então, estimula um futebol mais competitivo mais aguerrido o biótipo dos atletas mais fortes desenvolvidos faz com o futebol se torne mais agressivo mais forte. Do sudeste para cima você tem atletas mais habilidosos você tem uma escola brasileira mais temperada com ginga, com questões técnicas, mas eu diria que o futebol

Movimento, Porto Alegre, v. 17, n. 02, p. 195-210, abr/jun de 2011. 
brasileiro como um todo... Esta ginga eu atribuo à nossa origem de muita coisa a miscigenação racial fez um DNA com um biótipo (entrevistado 5)

Ainda que não dito explicitamente, o conceito de "raça" subjaz e foi revitalizado para sustentar a explicação dos entrevistados sobre a identidade do futebol "do Sul" em contraposição ao futebol "do Brasil". Enquanto a estética dos primeiros teria sido construída pela imigração, e a consequente presença do homem branco, a estética do segundo seria dada pela mistura das "raças", isto é, pela miscigenação.

Por outro lado, o fator histórico da miscigenação teria sido o primado da qualidade do povo brasileiro para as questões que dizem respeito ao uso do corpo. O "ser brasileiro" se aproxima do "ser mestiço", incluindo aí a presença do "ser negro" durante a miscigenação. Este argumento parece ter se cristalizado na memória coletiva como uma convicção nativa que é reconhecida pelos atores entrevistados e também reproduzida no interior da sociedade brasileira, através dos textos acadêmicos e jornalísticos, como o que segue abaixo, do ex-jogador Tostão:

Diferente da técnica, a habilidade é corporal, natural e instintiva. [...] A mistura de raças é um dos motivos da freqüente habilidade dos jogadores brasileiros. Além disso, como o Brasil é um país pobre, os meninos, em vez de passar todo o dia nas escolas, divertem-se com as bolas nas ruas" (TOSTÃO, 2006 - grifo dos autores) ${ }^{9}$

A representação dessa narrativa identitária sobre a estética do estilo de jogo brasileiro é explicada por uma espécie de argumento de "contágio". A identificação europeia de um estilo brasileiro de jogo que relaciona o futebol com o samba está enraizada no imaginário da sociedade brasileira. Mesmo acreditando no processo de intervenção e modernização do futebol operado junto aos atletas, os "especialistas" reproduzem a tradição construída por Gilberto Freyre sobre o futebol nacional.

${ }^{9}$ Estado de Minas, domingo, 12 de fevereiro de 2006, p. 34.

Movimento, Porto Alegre, v. 17, n. 02, p. 195-210, abr/jun de 2011. 
O samba, o carnaval e a capoeira, expressões culturais identificadas com a virtuose afro-brasileira, teriam influenciado esse estilo. Esse discurso se aproxima do que seria imaginado como um legado da "corporalidade africana" impressa na "identidade brasileira", como observado por DaMatta (1994, p. 16):

A essa altura cabe uma pergunta. Haveria, neste uso exclusivo dos pés que caracteriza o football association, uma relação inconsciente com o jogo de capoeira que os escravos africanos trouxeram para o Brasil? Jogo onde as armas de luta não são os punhos, mas as pernas e os pés?".

No plano do simbólico da cultura brasileira as representações sobre o "negro" são construídas à luz de uma "corporalidade" específica. Ele tem "força", mas também "ginga". Isso seria o diferencial da "raça negra" em relação ao "branco europeu" cuja virtuose seria agir racionalmente, em função dos objetivos em campo.

no sul, por exemplo, normalmente é um futebol de mais força até pela genética. A questão da própria população européia no sul e por isso que eles tem uma genética semelhante. No nordeste o futebol é muito mais solto, então, a tendência é fazer muito mais atacante. No nordeste os jogadores jogam em função do futebol livre, jogar por jogar (entrevistado 2).

é claro que se pegar a genética do atleta negro se pegar o atleta negro que tem explosão, como a questão da força seria mais visível no esporte coletivo mistura-se muito. A genética mesmo, o negro tem uma propensão maior de força. Vamos pegar a base da preparação física né, que é o atletismo em velocistas o potencial dos negros é maior a forca explosiva que é uma coisa importante no futebol (entrevistado 2).

As falas desse entrevistado parecem confirmar a tese de Sansone (1996) que disse que, no espaço do futebol, "ser negro" pode se constituir uma vantagem, como também pôde observar na epígrafe do texto de Witter (1982, p. 101): "Ó treineiro! É preciso 
colorir esse time. Só tem branquela! Põe crioulo, meu chapa". As mesmas representações foram apresentadas por Telles (2003, p. 241), considerando o discurso de uma professora do sul do Brasil, sobre os alunos pretos: "Eles só querem saber de samba e futebol. Está no sangue".

O corpo é o depositário do estabelecimento das fronteiras que definem, subjetivamente, "quem somos" (WOODWARD, 2000). História e memória são suportes de identidades individuais e coletivas que são processadas diacrônica e sincronicamente. Com efeito, as representações socialmente construídas sobre a "raça negra" se materializaram no universo simbólico da cultura brasileira, tal como observamos a partir da literatura e das falas dos atores entrevistados. Ciência e atores sociais funcionam no caso como guardiões da memória coletiva.

\section{ConsideraÇões Finals}

A partir da compreensão de que memórias coletivas são constituídas e constitutivas, podemos afirmar que as interpretações sobre a herança étnica desempenharam um papel importante na imaginação do nacionalismo brasileiro. No caso, as supostas aptidões corporais da "raça negra" para o futebol parecem ter servido para a construção positiva da identidade nacional. A partir das marcas distintivas da ginga, da alegria, da habilidade e sensualidade corporal, o negro teria transmitido ao futebol do País a representação do seu estilo de uso do corpo, num bom exemplo de como a comunidade imaginada "Brasil" se constrói com a incorporação das representações sobre a "raça negra".

Existe um coro de vozes que afirmam que, no atual estado da ciência, não há como estabelecer a superioridade ou inferioridade intelectual de uma raça, em relação à outra. Como declara Schwarcz (2003, p.184), a despeito dos critérios biológicos que balizavam as teorias raciais da sciencia do século XIX, a raça é uma "construção histórica e social": "antes de ser um conceito biológico, é uma 
realidade social, uma das formas de identificar as pessoas em nossa própria mente" (SCHWARCZ, 2003, p. 184).

Ainda assim, as idiossincrasias raciais continuam firmemente enraizadas no pensamento social. Sua ideia é amplamente compreendida e os efeitos desse conceito "imaginado" têm consequências reais. No plano coletivo, a revitalização desse conceito imaginado parece ter servido para a construção positiva da identidade nacional quando, por um lado, personifica - como dadas pela "raça" - as representações da arte, natureza, dom, agilidade ou habilidade da índole dionisíaca dos negros. Tais representações formam o discurso distintivo sobre a qualidade do futebol brasileiro em relação aos "outros". O negro teria, assim, emprestado a representação dionisíaca do uso do corpo para a construção da identidade brasileira (MURAD, 1994).

A memória coletiva se torna guia de ação para o entendimento das velhas representações sobre as identidades "raciais" internalizadas no plano simbólico da cultura brasileira. Objetivada nas formas primárias de julgamento que persistem na sociedade brasileira sobre "brancos" e "negros", ocorre, nesse caso, uma relação simbiótica em que as consciências coletivas e as consciências individuais se realimentam mútua e continuamente, num bom exemplo de como a consciência coletiva - no sentido de Durkheim - é incorporada ${ }^{10}$ no plano das consciências individuais.

Por fim, apesar das divisões entre a parte e todo, entre o sul e o Brasil, entre o futebol-força e o futebol-arte, o jogador Ronaldinho Gaúcho, com seu jogo de corpo e ginga, é a expressão que nossas construções e representações alimentam as demandas normativas da identidade.

\footnotetext{
${ }^{10 " C o n s i s t e ~ e m ~ m a n e i r a s ~ d e ~ a g i r, ~ d e ~ p e n s a r ~ e ~ d e ~ s e n t i r, ~ e x t e r i o r e s ~ a o ~ i n d i v i ́ d u o, ~ e ~ q u e ~ s a ̃ o ~}$ dotados de um poder de coerção em virtude do qual esses fatos se impõem a ele" (DURKHEIM, 1999, p. 3).
} 
Identities "Racial" and National Identity:
Representations of Black Body in the
Construction of the "Brazilian Style of Playing
Soccer"
Abstract: The authors examined the social representations built on the "black race" and its contribution to the identity development of the "Brazilian way of playing soccer". They investigated the anthropological literature of the subject and made semistructured interviews with the coaches of juniors and the professional categories, asking them if they recognized any differences in how soccer is played in Brazil, according to different regions. The given answers update the tradition of "Brazilian-style" - the Soccer-art - that polarizes the Soccer-force. The justifications on aesthetics of the Brazilian style drew on the ideology of miscegenation and the participation of African Americans in this process.

Keywords: soccer. Brazilian identity. racial representations.

\section{Las Identidades "Racial" y la "Identidad Nacional": Representaciones de Cuerpo Negro en la Construcción del "Estilo Brasileño de Jugar Fútbol"}

Resumen: Los autores examinaron las representaciones sociales construidas sobre la "raza negro" y su contribución al desarrollo de la identidad del "estilo brasileño de jugar al fútbol". Investigaran la literatura antropológica sobre el tema y hicieran entrevistas semi-estructuradas con los entrenadores de las categorías juvenil y profesional, preguntándoles si reconocen diferencias en las formas de se jugar al fútbol en Brasil, según las diferentes regiones. La respuestas actualizaran la tradición del "estilo brasileño" - el Fútbol-arte - polarizando el Fútbol-fuerza. Las justificaciones de la estética del estilo brasileño se basó en la ideología del mestizaje y de la participación de los negros en este proceso.

Palabras clave: fútbol. identidad brasileña. las representaciones raciales. 


\section{REFERÊNCIAS}

ARRUDA, Ângela. O ambiente natural e seus habitantes no imaginário brasileiro. In: ARRUDA, A. (Org.) Representando a alteridade. Petrópolis: Vozes, 1998. p.1746.

ARCHETTI, Eduardo. Masculinidades: fútbol, tango y polo en la Argentina. Buenos Aires: Antropofagia, 2003.

DAMATTA, Roberto. Esporte na sociedade: um ensaio sobre o futebol brasileiro. In: DAMATTA, R. (Org.) Universo do futebol: esporte e sociedade brasileira. Rio de Janeiro: Pinakotheke, 1982. p. 19 - 42.

. Antropologia do óbvio. Revista USP, São Paulo, n. 22, p. 10-17, 1994.

DAMO, Arlei Sander. Futebol e identidade social: uma leitura antropológica das rivalidades entre torcedores e clubes. Porto Alegre: Ed. Universidade/UFRGS, 2002.

DELGADO, Lucilia de A. N. Historia oral: memória, tempo, identidades. Belo Horizonte: Autêntica, 2006.

DURKHEIM, Emile. As regras do método sociológico. Tradução Paulo Neves. 2. ed. São Paulo: Martins Fontes, 1999.

FRANZINI, Fábio. Corações na ponta da chuteira: capítulos iniciais da história do futebol brasileiro (1919-1938). Rio de Janeiro: DP\&A, 2003.

FREYRE. Gilberto. Foot-ball mulatto. Diário de Pernambuco, Recife, 17 jun. 1938.

Sobrados e mucambos: decadência do patriarcado rural e desenvolvimento urbano. Rio de Janeiro: José Olympio, 1981. v. 1, v. 2.

GIULIANOTTI, Richard. Sociologia do futebol: dimensões históricas e socioculturais do esporte das multidões. São Paulo: Nova Alexandria, 2002.

GASTALDO, Édison; LEISTNER, Rodrigo. "A mais gaúcha de todas as Copas": identidade brasileira e imprensa esportiva na Copa do Mundo. Disponível em: <http:/ /www.utp.br/interin/Edicoes Anteriores/02/artigos/06_GastaldoLeistner_tematicalivre.pdf>. Acesso em: 28 fev. 2008.

MURAD, Maurício. Corpo, magia e alienação - o negro no futebol brasileiro: por uma interpretação sociológica do corpo como representação social. Rio de Janeiro, Departamento Cultural da UERJ, 1994.

OLIVEN, Ruben George. A parte e o todo: a diversidade cultural do Brasil-nação. 2. ed. Petrópolis, RJ: Vozes, 2006. 
SANSONE, Lívio. As relações raciais em Casa Grande \& Senzala revisitadas à luz do processo de internacionalização e globalização. In: MAIO, M. C.; SANTOS, R. V. (Org.). Raça, ciência e sociedade. Rio de Janeiro, FIOCRUZ, 1996. p.207-218.

SCHWARCZ, Lilia Moritz. Nem preto, nem branco, muito pelo contrário: cor e raça na intimidade. In: NOVAES, F. A.; SCHAWRCZ, L. M. (Org.). História da vida privada no Brasil. São Paulo: Companhia das Letras, 2003. v. 4, p. 173-245.

SOARES, Antonio Jorge. Futebol, raça e nacionalidade: releitura da história oficial. Tese (Doutorado) - Programa de Pós-Gradução em Educação Física, Universidade Gama Filho. São Paulo, 1998.

Futebol brasileiro e sociedade: a interpretação culturalista de Gilberto Freyre. In: ALABARCES, Pablo. (Org.). Futbologías: fútbol, identidade y iolência em América Latina. Buenos Aires: CLACSO, 2003. v. 1, p. 145-162.

TELLES, Edward. Racismo à brasileira: uma nova perspectiva sociológica. Rio de Janeiro: Relume Dumará, 2003.

TOLEDO, Luiz Henrique. Lógicas do futebol. São Paulo: Hucitec, 2002.

WITTER, José Sebastião. A várzea não morreu. In: MEIHY, J. C. S. (Org.). Futebol e cultura: coletânea de estudos. São Paulo: Imprensa Oficial do Estado, 1982. p. $101-104$.

WOODWARC. Kaith. Identidade e diferença: uma introdução teórica e conceitual. In: SILVA, Tadeu da (Org.). Identidade e diferença: a perspectiva dos estudos culturais. Petrópolis, RJ: Vozes, 2000. p. 7 - 72.

Endereço para correspondência:

Bruno Otávio de Lacerda Abrahão

Rua Chefe Pereira, 261, apto. 03 - Serra.

CEP 30240-150

Belo Horizonte - MG

Recebido em: 31.03.2011

Aprovado em: 19.06.2011

Movimento, Porto Alegre, v. 17, n. 02, p. 195-210, abr/jun de 2011. 
